DISCURSO 



\title{
DISCURSO LAUDATORIO A LA PATRIA
}

\author{
María del Carmen Ferrúa Allen ${ }^{1}$
}

Es para mí un gran honor y una gran responsabilidad dirigirme a ustedes a nombre de los miembros que conforman este claustro universitario, con motivo de rendir un homenaje a la patria y a la memoria de aquellos hombres y mujeres que lucharon por conseguir la libertad del dominio de una potencia extranjera, al conmemorarse un nuevo Aniversario de la Declaratoria y Proclamación de la Independencia del Perú.

En la búsqueda de un tema para desarrollar en este día, alusivo a las Fiestas Patrias, me pregunté ¿Qué significado tiene para los peruanos celebrar la Independencia de nuestra patria? Y en esa búsqueda a través de las diversas fuentes bibliográficas, encontré que en el pasado historiadores, sociólogos, políticos y muchos hombres de otras ciencias, también se habían hecho la misma pregunta, que se sigue repitiendo hasta el día de hoy. De ahí que este discurso laudatorio a la patria gira en torno a responder dicha pregunta.

\section{¿QUÉ SIGNIFICA CELEBRAR LA INDEPENDENCIA DEL PERÚ?}

Como todos sabemos, en unos cuatro días más, el 28 de julio del presente año, estaremos celebrando el centésimo nonagésimo cuarto (194\%) Aniversario de la Proclamación de la Independencia del Perú; recordaremos que hace 194 años, en 1821, en un acto público solemne, y ante una multitud de personas, el Capitán General don José de San Martín y Matorras, Libertador del Sur, declaró que: "El Perú es desde este momento libre e independiente por la voluntad general de los pueblos y por la justicia de su causa que Dios defiende" (Pons Muzzo, 2003).
Este hecho histórico es registrado por muchos como un acto que puede ser considerado de reivindicación de la patria y de la nación, sueño legítimo alcanzado por el pueblo peruano, en momentos que se difundían corrientes e ideologías de moda en Europa y que preconizaban la igualdad, justicia, libertad y fraternidad. Es, también, un reconocimiento a los precursores y los próceres de la Independencia quienes crearon el ambiente favorable para la llegada de estas corrientes e ideologías, que junto al esfuerzo y colaboración de hacendados y pobladores peruanos pudieron comprender que el cambio de mentalidad era necesario para la suerte del futuro de América, y más tarde, luego de enfrentamientos, luchas y combates se lograría sellar la independencia definitiva de nuestra patria.

Además, es una fecha que invita a tratar ciertos conceptos socio-políticos y culturales así como reflexionar sobre ellos: conciencia nacional, nacionalidad $e$ identidad nacional.

Con respecto al debate sobre la construcción de una conciencia nacional, el Dr. Aurelio Miró Quesada manifiesta que al finalizar el siglo XVIII, los hombres de las ciencias y de las letras no tenían una verdadera sensibilidad para lo indígena ni habían recogido los ideales patriotas de los precursores de la independencia, pues su concepto de Perú era el de criollos y en todo caso de mestizos, pues se consideraban descendientes de los conquistadores europeos, tanto en lo intelectual, el comercio libre como en lo económico. Es en los primeros años del siglo XIX que se va a producir un persistente y soterrado desarrollo de la conciencia nacional del Perú y de las formas como se manifestaría

1 Licenciada en Sociología en la Universidad Femenina del Sagrado Corazón. Con estudios concluidos en Doctorado en Educación) y en Maestría en Educación con mención en Docencia Universitaria. Tiene amplia experiencia laboral y profesional en instituciones públicas y privadas. Actualmente es Directora de Servicios Administrativos en la UNIFÉ. 
la naciente nacionalidad peruana. Esta situación surge a raíz de una reforma liberal y democrática, que finalmente no es llevada a cabo por el cambio de medidas políticas y militares de la autoridad virreinal, provocando una reacción de los espíritus de las gentes, que poco tiempo después conduciría a un cambio de actitud y un afloramiento de ideas separatistas hasta el momento en que se produciría la revolución libertadora.

El Dr. Miró Quesada señala que en los últimos años del Virreinato, ya era evidente que el Perú había pasado de una estratificación étnica a una imprecisa clasificación de grupos sociales y económicos basados en la diferenciación racial, geográfica (campo - ciudad, sierra - costa o viceversa) y social. Se podía distinguir grupos étnicos y sociales en el país que habían ido precisando su conciencia nacional acerca del Perú que querían, la cual se fue afianzando hasta llegar a la Emancipación. Es en el primer cuarto del siglo XIX que cada grupo social tenía su revolución, sus motivos y sus metas. Sin embargo, al final triunfaría, no la Revolución Indigenista y Restauradora sino la Revolución Americanista y Renovadora de los Patriotas de 1820, sembrada particularmente por los criollos intelectuales y apoyada por hombres sencillos de la ciudad y del campo, que más tarde culminaría con las Expediciones Libertadoras del Sur y del Norte encabezadas por los Generales José de San Martín y Simón Bolivar, respectivamente.

Los valores que triunfaron fueron la libertad política, la libertad económica, la soberanía popular, la democracia representativa, el libre pensamiento, la dignidad humana, la autodeterminación, la ilustración y las letras. En 1821, la Independencia era un concepto esencialmente político y jurídico, que tenía que estar incorporado a las condiciones $y$ a los fundamentos mentales de la época y como consecuencia natural había que pensar en una organización republicana, que resultara imprescindible para la libertad y la democracia, y porque los deberes ciudadanos, las virtudes republicanas, la moral cívica, son elementos indispensables para vivir libres sin temores.
El segundo concepto a aclarar en este proceso de la Independencia es la determinación de la nacionalidad. Era natural pensar en ese entonces en una integración entre lo nacional y lo continental o americano pero existiendo la imposibilidad real de comunicación, aún dentro de las similitudes globales, habían notorias diferencias, no solo locales sino regionales. Y luego de la Declaración del Cabildo de Lima por la Independencia del Perú, no solo de la dominación española sino de cualquiera otra dominación extranjera, se entendía que era importante pensar en la soberanía nacional, para que el nuevo gobierno que se instaurara tuviera autoridad sobre un territorio con fronteras claramente delimitadas, dentro de las cuales se pudiera ejercer el poder supremo.

Es así como por encima de todos los prejuicios de color o de clase, descontento, desmedro económico, rebelión contra la autoridad, no conformismo u otros de unos grupos sociales, aparece una fecunda comunidad con actitudes positivas que manifiestan sentimientos de patria, emoción por la tierra, creciente conciencia nacional, ansia de libertad, urgencia de autodeterminación, afirmación de la dignidad de la persona humana, igualdad ante la ley, y fe en la justicia. Al final del proceso independentista, se termina construyendo una unidad histórica de hombres e ideas que busca la inclusión y la integración sociales.

En cuanto al tercer concepto referido a la construcción de la identidad nacional, Fernando Fuenzalida manifiesta que la identidad tiene que ver con las semejanzas $y$ las diferencias que existen entre las personas, agrupaciones, grupos naturales o grupos sociales; y el proceso de la Independencia, como hemos visto, produce una transformación de carácter no racial, da paso a una transformación de carácter política, social y económica que permite la expansión y el desarrollo de un pueblo, de una comunidad. (Cátedra Perú, USMP)

Asimismo, el Dr. Max Hernández asevera que en nuestro país se dio un conjunto de realidades históricas y sociales que fueron definiendo nuestra propia identidad, la misma que, en su opinión continúa en permanente construcción, 
en cambio, en elaboración porque ella tiene que ver con el ser de la persona y con lo que es importante para uno u otro (Cátedra Perú, USMP); la construcción de la identidad es un proceso continuo de desarrollo y de definición del propio yo que formula un sentido propio de lo que somos y de nuestra relación con el mundo que nos rodea, siendo las fuentes de identidad más importantes: la nacionalidad o la etnicidad y la clase social (Giddens, 2006).

Entonces, pensar que el peruano no tiene identidad nacional es un error porque así como todo ser humano construye su propia identidad, toda colectividad define siempre su modo de ser, su modo de pensar y de comportarse. No existe un individuo ni colectividad nacional que no tenga rasgos propios, originales; lo que sí se puede señalar es que la identidad es sólida o débil. Al respecto, el sociólogo y docente universitario, Eduardo Arroyo (2006), manifiesta que si la identidad nacional se entiende como el arraigo de nuestras raíces, historia, valores, podemos decir que la experiencia peruana revela a una sociedad de identidades sólidas. Es una sociedad caracterizada por su complejidad y diversidad, características que deben ser trabajadas para lograr la unidad, la inclusión social, el respeto a la persona humana y a la naturaleza a fin de alcanzar el desarrollo sostenible como país para todos los peruanos.

Habiendo contestado a la interrogante anterior, la siguiente interrogante que nos debe animar a plantear como peruanos es:

\section{¿CÓMO CONMEMORAR LA INDEPENDENCIA EN EL AÑO 2021?}

Como todos sabemos, el Perú en el año 2021 cumpliría doscientos años de ser un país libre e independiente, y las celebraciones por los 200 años ya se iniciaron oficialmente, en agosto de 2014, en la ciudad del Cusco, con una propuesta innovadora: transformar esta conmemoración, durante una década, en una experiencia cultural y educativa descentralizada para consolidar una identidad nacional y plural. El proyecto bicentenario denominado: Camino hacia la libertad 2014-2021-2024 busca construir una visión integrada de la historia y del territorio que permita la afirmación de nuestra diversidad cultural. (El Peruano, agosto 2014).

Para el historiador Juan Luis Orrego Penagos (2010) este es el momento de abrir un debate nacional no solo sobre la independencia sino también acerca del largo proceso recorrido por los grupos humanos que habitan nuestro país a fin de entender su complejidad y diversidad en la construcción de una sociedad más dialogante y multicultural; se debe trabajar en temas que permitan vivir en comunidad y en democracia, con un profundo sentido de ciudadanía, entre los peruanos.

Hoy que se vive en un mundo globalizado donde los individuos, grupos y naciones se hacen más interdependientes, gracias al desarrollo de las tecnologías de la información y de la comunicación, que han intensificado la velocidad y el alcance de las interacciones que se establecen por todo el mundo exige que sepamos quiénes somos, de dónde venimos, qué país queremos ser y cuál es nuestra visión de hombre, sociedad y país que deseamos construir para las futuras generaciones de peruanos.

Muchas gracias y iViva el Perú! 


\section{REFERENCIAS}

Arroyo, Eduardo (2006). Perú: País de Identidades Sólidas. ¿Existe identidad nacional en el Perú? ¿En qué se basa la "peruanidad"? Construyendo nuestra Interculturalidad, Encuentros y Desencuentros. Abril. Tomado el 13 de julio de 2015. Disponible en Internet: http://interculturalidad. org/numero03/3_05.htm

El Peruano Diario Oficial. Celebraciones del Bicentenario. Publicado el 16 de agosto de 2014. Tomado el 14 de julio de 2015. Disponible en Internet: http://www.elperuano.com.pe/edicion/ default.aspx

Giddens, Anthony (2006). Sociología. Colaboración de Simon Griffiths. (5 $5^{\mathrm{a}}$ ed.) Madrid: Alianza Editorial S.A.

Hablandoclaro (2011). ¿Qué significa ser peruano? Marzo 27. Tomado el 13 de julio de 2015. Disponible en Internet: https://hablandoclaroperu.wordpress.com/2011/03/27/\%C2\%BFquesignifica-ser-peruano/

Klaiber, Jeffrey L. (1980) Independencia, Iglesia y Clases Populares. (1 ${ }^{\mathrm{a}}$ ed.) Lima: Universidad del Pacífico. Abril, pp. 49-54

Miró Quesada, Aurelio (1970). Idea del Perú. Conferencias dictadas por encargo de la Comisión Nacional del Sesquicentenario de la Independencia del Perú. Lima, pp. 41-44

Orrego, Juan Luis (2010). El Perú y su próximo bicentenario. Ideele Revista No 229. Tomado el 13 de julio de 2015. Disponible en Internet: http://revistaideele.com/ideele/content/el-per\%C3\%BAy-su-pr\%C3\%B3ximo-bicentenario

Orrego Penagos, Juan Luis (2010). 28/07/10: Hacia el Bicentenario: ¿Cómo conmemorar la Independencia en 2021? Rumbo al Bicentenario. Blog de Historia del Perú, América Latina y el Mundo. Siglos XIX y XX. Tomado el 13 de julio de 2015. Disponible en Internet: http:// blog.pucp.edu.pe/blog/juanluisorrego/2010/07/28/hacia-el-bicentenario-como-conmemorar-laindependencia-en-2021/

Pons Muzzo, Gustavo (2003). La Declaración y la Proclamación de la Independencia y los Símbolos de la Patria. ( $1^{\mathrm{a}}$ ed.) Lima: Editorial Imprenta Unión de la Universidad Peruana Unión. pp.117 Universidad San Martín de Porres. Tema: Qué Significa Ser Peruano Hoy en Día. XIII Sesión de Exposiciones. Cátedra Perú. Tomado el 13 de julio de 2015. Disponible en Internet: http://www. usmp.edu.pe/catedraperu/index.php? $\mathrm{p}=$ trececonferencia 